\title{
Suplementação de betaglucano a dietas de leitões de 21 a 60 dias de idade
}

\author{
[Beta-glucon suplementacion in diets for piglets from 21 to 60 days of age] \\ C.B.S. Mendes ${ }^{1}$, D.O. Fontes ${ }^{2 *}$, R.M.C. Guedes ${ }^{2}$, F.C.O. Silva ${ }^{3}$, M.A. Silva ${ }^{2}$, J.S.V. Oliveira ${ }^{4}$, \\ I.S. Fernandes ${ }^{4}$, F.A.P.V.Fontes ${ }^{1}$ \\ ${ }^{1}$ Aluno de pós-graduação - EV-UFMG - Belo Horizonte, MG \\ ${ }^{2}$ Escola de Veterinária - UFMG \\ Caixa Postal 567 \\ 30123-970 - Belo Horizonte, MG \\ ${ }^{3}$ EPAMIG - Viçosa, MG \\ ${ }^{4}$ Aluno de graduação - EV-UFMG, Belo Horizonte, MG
}

\begin{abstract}
RESUMO
Realizou-se um experimento com 1.500 leitões distribuídos em delineamento experimental de blocos ao acaso com cinco tratamentos: controle e com suplementação de 60, 120, 180 e 240g de betaglucano por tonelada de dieta. Foram analisadas as variáveis ganho de peso diário, peso final, consumo de dieta diário e conversão alimentar nos períodos de 21 a 35, 21 a 49 e 21 a 60 dias de idade. Houve aumento linear significativo do peso final e do ganho de peso diário de leitões suplementados com betaglucano na dieta dos 21 aos 60 dias de idade. A inclusão de $240 \mathrm{~g} / \mathrm{ton}$. proporcionou aumento no peso final de $800 \mathrm{~g}$, o que corresponde ao aumento de 3,2\% em relação aos animais do grupo-controle. O ganho de peso diário foi $4,7 \%$ mais alto para o grupo de animais tratados com $240 \mathrm{~g} / \mathrm{ton}$. Não se observou efeito significativo dos tratamentos sobre: consumo diário de dieta, conversão alimentar, atividade da enzima superóxido dismutase nem sobre a resposta imune.
\end{abstract}

Palavras-chave: leitão, betaglucano, desempenho, sistema imune, superóxido dismutase

\begin{abstract}
A total of 1,500 piglets were used in a completely randomized experimental block design to study the effects of beta-glucon level (control, 60, 120, 180, and 240g per ton of diet) on daily weight gain, body weight, daily feed intake and feed: weight gain ratio from 21 to 35, 21 to 49 and from 21 to 60 days of age Positive and significant linear effects of beta-gluton on body weight and daily weight gain of piglets from 21 to 60 days of age were observed. The inclusion of $240 \mathrm{~g}$ of beta-gluton in diet resulted in $800 \mathrm{~g}$ increase in body weight which corresponds to $3.25 \%$ increase in body weight and $4.7 \%$ increase in daily weight gain in comparison to animals of the control group. No effects of beta-gluton supplementation on feed intake, feed: weight gain ratio and superoxide dismutase enzyme activity or animal immune response were observed.
\end{abstract}

Keywords: piglet, beta-glucan, performance, immune system, superoxide dismutase

\section{INTRODUÇÃO}

A fase de creche é considerada crítica para os leitões. Isto se deve a vários fatores estressantes que ocorrem simultaneamente em razão do desmame. Esses fatores relacionam-se, principalmente, com a separação dos leitões da mãe, troca de ambiente, idade ao desmame e mudança na alimentação, de dieta líquida para dieta sólida.

Para o animal jovem, o desmame significa a perda da mãe, do grupo social já estabelecido e do ambiente conhecido. As profundas alterações

Recebido em 10 de novembro de 2009

Aceito em 14 de junho de 2010

* Autor para correspondência (corresponding author)

E-mail: daltonfontes@ufmg.br 
sociais e ambientais relacionadas ao desmame em suínos manifestam-se frequentemente em parada do crescimento durante o período pósdesmame, resultando em perdas econômicas significativas para a indústria (McCracken et al., 1995).

O desmame dos leitões entre 21 e 28 dias de idade é prática comum em razão de permitir maior produtividade das matrizes - número de leitegadas por ano e número de leitões desmamados por porca por ano. O desmame, nessa idade, requer modificações de manejo, nutrição, ambiente e sanidade. Inúmeras pesquisas têm evidenciado a necessidade de fornecer dieta com alta palatabilidade, digestibilidade e densidade nutricional em prédesmame e pós-desmame, para se conseguir bom desempenho no período inicial de vida (até cerca $30 \mathrm{~kg}$ de peso). O fornecimento de dieta com baixo valor nutricional, pobre em energia, sem lactose e rica em carboidratos que o leitão ainda não consegue digerir, pode levar à perda de peso, justamente por não conseguir ajustar seu hábito alimentar às mudanças bruscas de nutrientes da dieta (Lima et al., 1997). Diante desses fatos, tem-se o desafio de melhorar o desempenho dos leitões no período pós-desmame, pelo uso de aditivos alimentares.

Existe, hoje, certa pressão para proibir o uso de antibióticos como promotores de crescimento. Essa proibição deve-se à possibilidade de ocorrer resistência bacteriana cruzada, que provocaria menor eficiência do antibiótico à terapia (animal e humana), e à emergente exigência dos importadores por produtos livres de resíduos antibióticos (Soncini, 1999; Silva, 2000). Uma alternativa para reduzir o uso de antibióticos na alimentação animal é buscar outros aditivos que tenham efeito positivo, em especial sobre a criação de leitões. Dentre os aditivos, destacamse os pré-bióticos, que servem de alimento e estimulam o crescimento de diversas bactérias intestinais não patogênicas (Bandeira et al., 2007).

Os pré-bióticos extraídos de leveduras, ricos em betaglucano, podem ter importante papel na fase de creche, pois, ao inibirem a colonização de microrganismos indesejáveis no trato gastrintestinal, como Escherichia coli, e dificultarem a ação de metabólitos tóxicos que influenciam a fisiologia da mucosa, contribuem positivamente para a saúde intestinal dos leitões (Gibson e Roberfroid, 1995). Consequentemente, há melhora na digestão, absorção e retenção dos nutrientes da dieta, o que influi positivamente no desempenho (Spring, 2000). Ao estimularem o crescimento das bactérias produtoras de ácido láctico, os pré-bióticos atuam de forma benéfica sobre o sistema imune do hospedeiro, pois estimulam a produção de citocinas, a proliferação de células mononucleares, a fagocitose macrofágica e a indução na síntese de grandes quantidades de imunoglobulinas, em especial as imunoglobulinas do tipo A (Yasui e Ohwaki, 1991; MacFarlane e Cummings, 1999). Assim, os betaglucanos, ao modularem a resposta imunológica, preparam melhor os animais aos desafios sanitários. Outro benefício do uso dos pré-bióticos é o estímulo à produção de anticorpos.

O objetivo deste trabalho foi avaliar o efeito da suplementação de betaglucano à dieta sobre as características de desempenho e resposta imune de leitões do desmame, aos 60 dias de idade.

\section{MATERIAL E MÉTODOS}

O experimento foi realizado entre setembro e dezembro de 2007. As baias onde os animais foram alojados eram suspensas, possuíam piso de concreto semirripado e ficavam em galpão de alvenaria coberto com telhas de barro e com sistema de fechamento (cortinas). Em cada baia, havia dois bebedouros do tipo chupeta, instalados em ângulo de $45^{\circ}$ e altura regulável (altura mínima de $25 \mathrm{~cm}$ ) e dois comedouros convencionais de metal, onde sete animais em cada comedouro comiam ao mesmo tempo. As baias também dispunham de uma área de $0,24 \mathrm{~m}^{2} /$ animal.

Foram utilizados 1.500 leitões híbridos comerciais, recém-desmamados, machos castrados e fêmeas, originados de linhagens selecionadas geneticamente para deposição de carne magra (Agrocres-Pic), com peso inicial da unidade experimental (baia) de $6,31 \pm 0,41 \mathrm{~kg}$. Os animais foram distribuídos em delineamento experimental de blocos ao acaso, com cinco tratamentos: controle e com adição de 60, 120, 180 e $240 \mathrm{~g}$ de betaglucano por tonelada de dieta, 10 repetições e 30 animais por unidade experimental (baia). A idade inicial foi $21 \pm 2$ dias (idade ao desmame). 
As dietas, formuladas para atender às exigências nutricionais dos leitões e estabelecidas por Rostagno (2005), foram fornecidas à vontade, durante todo período experimental. O programa nutricional utilizado foi dividido em quatro fases: dieta pré-zero ( 21 a 28 dias de idade), dieta préinicial I (28 a 35 dias de idade), dieta pré-inicial II (35 a 49 dias de idade) e dieta inicial (49 a 60 dias de idade). O betaglucano, adicionado em substituição ao inerte, foi um aditivo pré-biótico, extraído de uma cepa especialmente selecionada de Saccharomyces cerevisiae (Betamune, Biorigin - São Paulo, Brasil). A dieta pré-zero correspondia à dieta comercial pronta. As demais foram preparadas na granja e estão descritas nas Tab. 1,2 e 3.

Tabela 1. Composição centesimal das dietas fornecidas aos leitões no período de 28 a 35 dias de idade

\begin{tabular}{|c|c|c|c|c|c|}
\hline \multirow{2}{*}{ Ingrediente } & \multicolumn{5}{|c|}{ Suplementação de betaglucano à dieta } \\
\hline & Controle & $60 \mathrm{~g} / \mathrm{t}$ & $120 \mathrm{~g} / \mathrm{t}$ & $180 \mathrm{~g} / \mathrm{t}$ & $240 \mathrm{~g} / \mathrm{t}$ \\
\hline Milho grão (kg) & 33,280 & 33,280 & 33,280 & 33,280 & 33,280 \\
\hline Farelo de soja (kg) & 20,000 & 20,000 & 20,000 & 20,000 & 20,000 \\
\hline Açúcar $(\mathrm{kg})$ & 5,200 & 5,200 & 5,200 & 5,200 & 5,200 \\
\hline Óleo degomado (kg) & 1,200 & 1,200 & 1,200 & 1,200 & 1,200 \\
\hline Concentrado $\mathrm{P} 400^{1}(\mathrm{~kg})$ & 40,000 & 40,000 & 40,000 & 40,000 & 40,000 \\
\hline Amphenor $^{2}(\mathrm{~kg})$ & 0,200 & 0,200 & 0,200 & 0,200 & 0,200 \\
\hline L-Lisina $\mathrm{HCl}-78,4 \%(\mathrm{~kg})$ & 0,090 & 0,090 & 0,090 & 0,090 & 0,090 \\
\hline Inerte $(\mathrm{kg})$ & 0,030 & 0,024 & 0,018 & 0,012 & 0,006 \\
\hline Betaglucano (kg) & - & 0,006 & 0,012 & 0,018 & 0,024 \\
\hline Total & 100,00 & 100,00 & 100,00 & 100,00 & 100,00 \\
\hline
\end{tabular}

${ }^{1}$ Níveis de garantia (por $\mathrm{kg}$ do produto): zinco 4.660,00mg; lisina 7.410,00mg; metionina 4.900,00mg; vit. E 240,00UI.; manganês $97,00 \mathrm{mg}$; vit. $\mathrm{B}_{12} 75,00 \mathrm{mcg}$; iodo $4,45 \mathrm{mg}$; ácido pantotênico 42,00mg; cobre 250,00mg; ácido fólico 6,00mg; niacina 75,00mg; colistina 100,00mg; salinomicina 12,00mg; ferro 172,00mg; colina 720,00mg; cobalto $0,75 \mathrm{mg}$; BHT 24,00mg; ácido fumárico $33.700,00 \mathrm{mg}$; selênio $1,10 \mathrm{mg}$; vit. $\mathrm{D}_{3}$ 9.000,00UI; vit. A $36.000,00 \mathrm{UI}$; vit. $\mathrm{B}_{6} 9,00 \mathrm{mg}$; vit. $\mathrm{K}_{3} 9,00 \mathrm{mg}$; biotina $0,70 \mathrm{mg}$; vit. $\mathrm{B}_{1} 7,50 \mathrm{mg}$.

${ }^{2}$ Nível de garantia (por kg do produto): florfenicol 20g.

Tabela 2. Composição centesimal das dietas fornecidas aos leitões no período de 35 a 49 dias de idade

\begin{tabular}{|c|c|c|c|c|c|}
\hline \multirow{2}{*}{ Ingrediente } & \multicolumn{5}{|c|}{ Suplementação de betaglucano à dieta } \\
\hline & Controle & $60 \mathrm{~g} / \mathrm{t}$ & $120 \mathrm{~g} / \mathrm{t}$ & $180 \mathrm{~g} / \mathrm{t}$ & $240 \mathrm{~g} / \mathrm{t}$ \\
\hline Milho grão & 39,130 & 39,130 & 39,130 & 39,130 & 39,130 \\
\hline Farelo de soja & 24,000 & 24,000 & 24,000 & 24,000 & 24,000 \\
\hline Açúcar & 5,200 & 5,200 & 5,200 & 5,200 & 5,200 \\
\hline Óleo degomado & 1,600 & 1,600 & 1,600 & 1,600 & 1,600 \\
\hline Concentrado P300 ${ }^{1}$ & 30,000 & 30,000 & 30,000 & 30,000 & 30,000 \\
\hline Biomox $^{2}$ & 0,040 & 0,040 & 0,040 & 0,040 & 0,040 \\
\hline Inerte $(\mathrm{kg})$ & 0,030 & 0,024 & 0,018 & 0,012 & 0,006 \\
\hline Betaglucano (kg) & - & 0,006 & 0,012 & 0,018 & 0,024 \\
\hline Total & 100,00 & 100,00 & 100,00 & 100,00 & 100,00 \\
\hline
\end{tabular}

${ }^{\mathrm{T}}$ Níveis de garantia (por kg do produto): ferro 230,00mg; colina 1.620,00mg; tilosina 168,00mg; ácido fumárico 33.300,00mg; metionina 5.029,00mg; niacina 84,00mg; zinco 695,00mg; cobalto 1,00mg; B.H.T. 27,00mg; vit. $\mathrm{D}_{3}$ $10,00 \mathrm{UI}$; vit. $\mathrm{K}_{3} 10,00 \mathrm{mg}$; cobre $335,00 \mathrm{mg}$; manganês $130,00 \mathrm{mg}$; selênio $1,45 \mathrm{mg}$; vit. $\mathrm{B}_{2} 12,50 \mathrm{mg}$; vit. E 268,00UI; vit. $\mathrm{B}_{12} 84,00 \mathrm{mcg}$; vit. $\mathrm{B}_{6} 10,00 \mathrm{mg}$; biotina $1,00 \mathrm{mg}$; vit. $\mathrm{B}_{1} 8,40 \mathrm{mg}$; lisina $7.800,00 \mathrm{mg}$; ácido fólico 7,00mg; ácido pantotênico $47,00 \mathrm{mg}$; vit. A $40.200,00 \mathrm{UI}$; iodo $6,00 \mathrm{mg}$.

${ }^{2}$ Nível de garantia (por kg do produto): amoxicilina 500g. 
Suplementação de betaglucano...

Tabela 3. Composição centesimal das dietas fornecidas aos leitões no período de 35 a 49 dias de idade

\begin{tabular}{|c|c|c|c|c|c|}
\hline \multirow{2}{*}{ Ingrediente } & \multicolumn{5}{|c|}{ Nível de betaglucano } \\
\hline & Controle & $60 \mathrm{~g} / \mathrm{t}$ & $120 \mathrm{~g} / \mathrm{t}$ & $180 \mathrm{~g} / \mathrm{t}$ & $240 \mathrm{~g} / \mathrm{t}$ \\
\hline Milho grão & 51,670 & 51,670 & 51,670 & 51,670 & 51,670 \\
\hline Farelo de soja & 30,800 & 30,800 & 30,800 & 30,800 & 30,800 \\
\hline Açúcar & 5,200 & 5,200 & 5,200 & 5,200 & 5,200 \\
\hline Óleo degomado & 2,000 & 2,000 & 2,000 & 2,000 & 2,000 \\
\hline Concentrado $1100^{1}$ & 10,000 & 10,000 & 10,000 & 10,000 & 10,000 \\
\hline Biomox $^{2}$ & 0,040 & 0,040 & 0,040 & 0,040 & 0,040 \\
\hline Colistina $^{3}$ & 0,100 & 0,100 & 0,100 & 0,100 & 0,100 \\
\hline L-Lisina $\mathrm{HCl}-78,4 \%$ & 0,160 & 0,160 & 0,160 & 0,160 & 0,160 \\
\hline Inerte $(\mathrm{kg})$ & 0,030 & 0,024 & 0,018 & 0,012 & 0,006 \\
\hline Betaglucano (kg) & - & 0,006 & 0,012 & 0,018 & 0,024 \\
\hline Total & 100,00 & 100,00 & 100,00 & 100,00 & 100,00 \\
\hline
\end{tabular}

${ }^{\mathrm{T}}$ Níveis de garantia (por kg do produto): vit. $\mathrm{B}_{12}$ 250,00mcg; ferro 580,00mg; vit. A 120.000,00UI; iodo 15,00mg; BHT 80,00mg; colina 3.600,00mg; biotina 2,40mg; vit. $\mathrm{D}_{3} 30.000,00 \mathrm{UI}$; ácido pantotênico $140,00 \mathrm{mg}$; selênio 3,65mg; zinco $1.635,00 \mathrm{mg}$; ácido fólico 20,00mg; vit. E $800 \mathrm{UI}$; cobalto 2,50mg; niacina 250,00mg; vit. $\mathrm{B}_{2} 50,00 \mathrm{mg}$; metionina 9.900,00mg; cobre 844,00mg; vit. $\mathrm{B}_{6} 30,00 \mathrm{mg}$; lisina $18.330,00 \mathrm{mg}$; manganês $325,00 \mathrm{mg}$; vit. $\mathrm{B}_{1} 25,00 \mathrm{mg}$; vit. $\mathrm{K}_{3} 30,00 \mathrm{mg}$; salinomicina $360,00 \mathrm{mg}$.

${ }^{2}$ Nível de garantia (por kg do produto): amoxicilina $500 \mathrm{~g}$.

${ }^{3}$ Nível de garantia (por kg do produto): sulfato de colistina $100 \mathrm{~g}$.

Os animais, pesados individualmente aos 21 dias de idade, foram distribuídos nos tratamentos de forma que todas as baias apresentassem peso médio inicial semelhante. Foram feitas pesagens periódicas da dieta e das sobras. Os dados de consumo de dieta foram obtidos pela soma do consumo de dieta em cada período.

Os parâmetros de desempenho avaliados foram: peso aos 35, 49 e 60 dias de idade; ganho de peso diário (GPD) dos 21 a 35, 21 a 49 e 21 a 60 dias de idade; consumo de dieta diário (CRD) dos 21 a 35, 21 a 49 e 21 a 60 dias de idade e conversão alimentar (CA) dos 21 a 35, 21 a 49 e 21 a 60 dias de idade. Aos 35, 49 e 60 dias de idade, os animais foram pesados em conjunto (unidade experimental ou baia) para obtenção do peso médio. A conversão alimentar foi calculada considerando o consumo de dieta e o ganho de peso dos leitões ao final de 35, 49 e 60 dias de idade.

A ativação do sistema imune dos leitões foi obtida por meio de vacinação contra pneumonia enzoótica, pois a granja encontrava-se livre do agente contido na vacina. Utilizou-se bacterina de Mycoplasma hyopneumoniae, (M+PAC Schering-Plough - New Jersey, EUA) administrada em um animal de cada tratamento. Os leitões foram vacinados $(1 \mathrm{~mL})$ no momento do alojamento na baia experimental e 15 dias após (dose reforço - 1mL). Dos animais vacinados identificados por brincos, foram coletadas amostras de sangue em quatro momentos distintos: momento do alojamento $\left(\mathrm{t}_{0}\right)$, 15 dias após o alojamento $\left(\mathrm{t}_{1}\right), 30$ dias após o alojamento $\left(\mathrm{t}_{2}\right)$ e ao término do experimento $\left(\mathrm{t}_{3}\right)$. $\mathrm{O}$ sangue foi colhido com seringa e agulha descartáveis de $5 \mathrm{~mL}$. Após a coleta, o sangue foi transferido para um tubo de vácuo (Vacutainer), com capacidade para $4 \mathrm{~mL}$, sem anticoagulante. Os tubos foram deixados por cerca, de seis horas em temperatura ambiente para retração do coágulo. O soro retirado do tubo de vácuo por meio de seringa estéril foi colocado em Eppendorf, identificado e congelado. O material foi enviado sob refrigeração ao laboratório da MICROVET, em Viçosa para realização de sorologia pareada (ELISA) para $M$. hyopneumoniae, a fim de verificar diferenças de resposta humoral aos tratamentos. O ELISA utilizou o kit comercial K004321-9 da Oxoid Limited, com anticorpo monoclonal altamente específico contra um epítopo - sítio de ligação específico que é reconhecido por um anticorpo, de $M$. hyopneumoniae. Assim, realizou-se um ELISA por competição. A leitura da densidade ótica (DO) foi realizada em espectrofotômetro com filtro de $492 \mathrm{~nm}$.

Ao final do experimento, foram escolhidos, aleatoriamente, 10 animais de cada tratamento da 
última repetição e deles colhidas amostras de sangue para a determinação da atividade da enzima superóxido dismutase (SOD). Após a coleta, o sangue foi transferido para um tubo de vácuo com anticoagulante ácido etilenodiamino tetra-acético (EDTA) e capacidade para $4 \mathrm{~mL}$. Todas as amostras, conservadas por seis horas sob refrigeração, foram mantidas por 30 dias em temperatura próxima a $-80^{\circ} \mathrm{C}$. As amostras, encaminhadas ao Laboratório de Membranas Excitáveis (Lamex) do Instituto de Ciências Biológicas da UFMG, foram mantidas ainda a $80^{\circ} \mathrm{C}$, por mais 15 dias. As amostras foram, então, homogeneizadas com $0,01 \mathrm{~mol} / \mathrm{L}$ de tampão fosfato de sódio $(\mathrm{pH} \mathrm{7,4)} \mathrm{e} 0,03 \mathrm{~mol} / \mathrm{L}$ de $\mathrm{KCl}$ de forma a restabelecer a SOD e, em seguida, centrifugadas por cerca de cinco minutos. Às amostras $(40 \mu \mathrm{L}$ de sangue) foi acrescentado $1 \mathrm{~mL}$ de tampão Tris- $\mathrm{HCl}(\mathrm{pH} \mathrm{8,2),}$ que continha $1 \mathrm{mmol} / \mathrm{L}$ de ácido dietilenotriaminopentacético (DTPA). Em seguida, acrescentaram-se $0,2 \mathrm{mmol} / \mathrm{L}$ de pirogalol. A técnica utilizada para determinar a atividade da SOD baseou-se na inibição da reação do radical superóxido pelo pirogalol, que é um composto que se auto-oxida com a variação de pH. Em meio básico, a auto-oxidação do pirogalol gera superóxido. A SOD compete com o sistema de detecção pelo radical superóxido.
Uma vez que não se pode determinar a concentração da enzima nem sua atividade na forma de substrato consumido/tempo, utiliza-se uma unidade relativa. Define-se uma unidade de SOD como a quantidade de enzima necessária para inibir a velocidade de oxidação do detector em $50 \%$ do seu valor original. A oxidação do pirogalol forma um produto colorido, detectado espectrofotometricamente a $420 \mathrm{~nm}$, durante três minutos. Determinou-se a atividade da SOD por meio da velocidade de formação do pirogalol oxidado.

Os dados de desempenho e da atividade da enzima superóxido desmutase (SOD) foram submetidos a análises de variância pelo pacote estatístico computacional SAEG (Sistema... 2007), utilizando estudos de modelos de regressão linear e/ou quadrático. Os dados de sorologia foram submetidos à análise não paramétrica ao nível de $5 \%$ de probabilidade (teste Kruskal-Wallis).

\section{RESULTADOS E DISCUSSÃO}

Os resultados do peso, ganho de peso, consumo de dieta e conversão alimentar dos 21 aos 35, 21 aos 49 e 21 aos 60 dias de idade encontram-se na Tab. 4.

Tabela 4. Pesos aos 35, 49 e 60 dias, ganho de peso diário, consumo de dieta diário e conversão alimentar (CA) de suínos dos 21 aos 60 dias de idade, de acordo com a suplementação de betaglucano à dieta

\begin{tabular}{|c|c|c|c|c|c|c|c|}
\hline \multirow{2}{*}{$\begin{array}{l}\text { Período } \\
\text { (dias) }\end{array}$} & \multirow{2}{*}{ Parâmetros } & \multicolumn{5}{|c|}{ Suplementação de betaglucano da dieta (g/t) } & \multirow{2}{*}{$\begin{array}{l}\mathrm{CV} \\
(\%)\end{array}$} \\
\hline & & 0 & 60 & 120 & 180 & 240 & \\
\hline \multirow{5}{*}{21 a 35} & Peso inicial $(\mathrm{kg})$ & 6,22 & 6,31 & 6,29 & 6,23 & 6,24 & \\
\hline & Peso aos 35 dias (kg) & 8,95 & 9,18 & 9,07 & 9,14 & 9,04 & 3,54 \\
\hline & Ganho de peso diário (g) & 184 & 202 & 195 & 200 & 193 & 13,34 \\
\hline & Consumo de dieta diário $(\mathrm{g})$ & 249 & 287 & 270 & 287 & 271 & 11,74 \\
\hline & Conversão alimentar (g/g) & 1,36 & 1,46 & 1,41 & 1,46 & 1,43 & 15,68 \\
\hline \multirow{4}{*}{21 a 49} & Peso aos 49 dias $(\mathrm{kg})$ & 16,7 & 16,58 & 16,5 & 16,61 & 16,75 & 4,76 \\
\hline & Ganho de peso diário (g) & 372 & 369 & 366 & 370 & 374 & 7,79 \\
\hline & Consumo de dieta diário $(\mathrm{g})$ & 507 & 519 & 520 & 522 & 518 & 7,59 \\
\hline & Conversão alimentar $(\mathrm{g} / \mathrm{g})$ & 1,36 & 1,42 & 1,48 & 1,41 & 1,39 & 12,28 \\
\hline \multirow{4}{*}{21 a 60} & Peso final $(\mathrm{kg})^{1}$ & 24,06 & 24,08 & 24,64 & 24,63 & 24,86 & 4,03 \\
\hline & Ganho de peso diário $(\mathrm{g})^{1}$ & 443 & 444 & 459 & 459 & 464 & 5,41 \\
\hline & Consumo de dieta diário (g) & 681 & 686 & 701 & 712 & 691 & 5,83 \\
\hline & Conversão alimentar $(\mathrm{g} / \mathrm{g})$ & 1,54 & 1,55 & 153 & 1,55 & 1,49 & 5,18 \\
\hline
\end{tabular}

\footnotetext{
${ }^{1}$ Efeito linear $(\mathrm{P}<0,05)$
} 
Não houve efeito $(P>0,05)$ da suplementação de betaglucano sobre o GPD, CRD e CA dos leitões, do desmame aos 35 dias e 49 dias de idade. Possivelmente, isso ocorreu em razão do curto período no qual os animais foram submetidos aos tratamentos. Entretanto, quando analisado todo o período experimental - dos 21 aos 60 dias de idade , observou-se aumento $(\mathrm{P}<0,05)$ linear do peso final $(\mathrm{Y}=23,9262+0,00318704 \mathrm{X}-\mathrm{R} 2=0,72)$ e do ganho de peso $(\mathrm{Y}=0,44082+0,000084861 \mathrm{X}-\mathrm{R} 2$ $=0,78)$ dos leitões suplementados com betaglucano na dieta (Fig. 1 e 2). Dessa forma, a inclusão de $240 \mathrm{ppm}$ de betaglucano proporcionou aumento no peso final de 800 gramas, o que corresponde à variação de 3,2\% em relação aos animais do grupocontrole. Esse aumento linear no peso final acarretou efeito semelhante sobre o GPD 4,7\% mais alto para os leitões do grupo tratado com 240ppm de betaglucano. Li et al. (2006) encontraram melhora de $12,7 \%$ no ganho de peso dos leitões suplementados com $50 \mathrm{ppm}$ de betaglucano, e Eicher et al. (2006) observaram que o ganho de peso foi significativamente influenciado pelos tratamentos, e foi maior nos leitões que receberam a combinação de betaglucano e vitamina C. Entretanto, Dritz et al. (1995) e Hahn et al. (2006) não verificaram diferenças significativas no ganho de peso e no peso final dos leitões. Os mesmos autores, ao utilizarem betaglucano com antibióticos, também não encontraram efeito significativo para o ganho de peso.

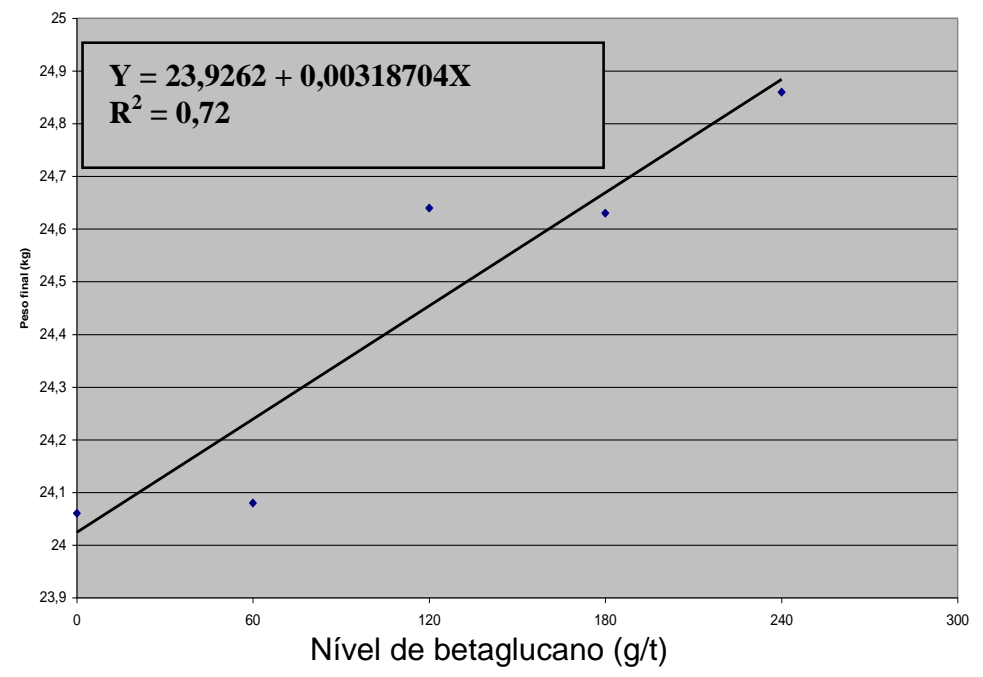

Figura 1. Peso dos suínos aos 60 dias de idade, em função da suplementação de betaglucano à dieta.

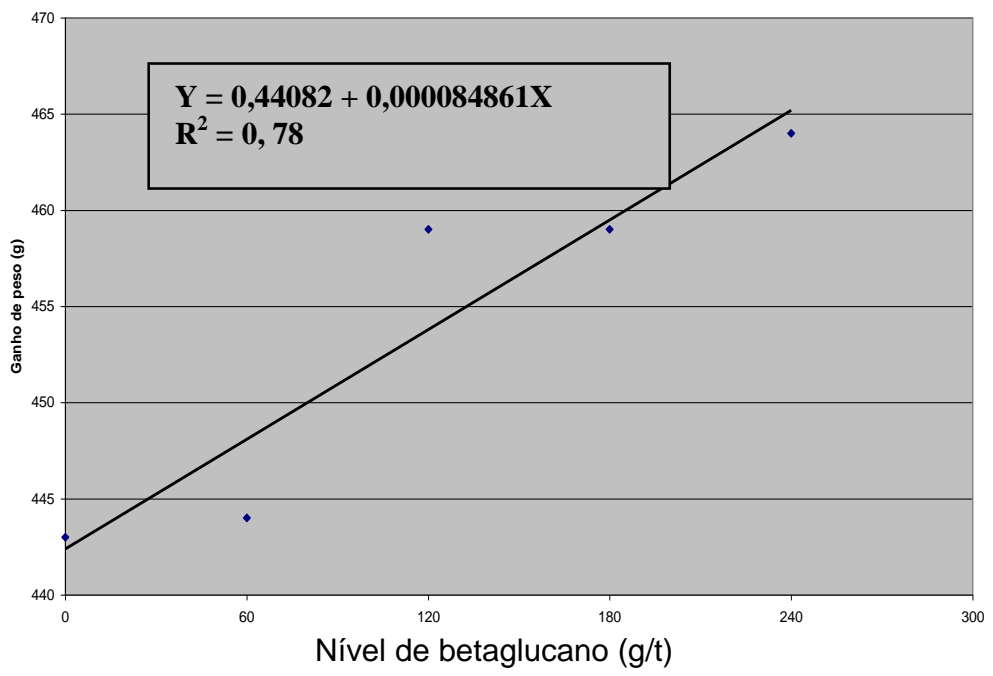

Figura 2. Ganho de peso diário de suínos dos 21 aos 60 dias de idade em função da suplementação betaglucano à dieta. 
Não se observou efeito $(\mathrm{P}>0,05)$ significativo dos tratamentos sobre o CRD. Resultados semelhantes também foram relatados por Dritz et al. (1995) e Hahn et al. (2006) que não observaram qualquer mudança no consumo para diferentes inclusões de betaglucano. Entretanto, $\mathrm{Li}$ et al. (2006) observaram efeito positivo do tratamento sobre o consumo de dieta, o que influenciou também o ganho de peso final dos leitões.

Não houve efeito $(\mathrm{P}>0,05)$ da suplementação de betaglucano sobre a CA. Entretanto, no nível de 240 gramas de betaglucano por tonelada de dieta, pode-se observar alteração, não significativa, de $3,3 \%$ na CA em relação ao grupo-controle. Dritz et al. (1995) não encontraram efeito significativo sobre a conversão alimentar. Resultados semelhantes também foram encontrados por Hahn et al. (2006) e Li et al. (2006).

Essa discrepância nos resultados dá-se, provavelmente, pelas diferenças na dosagem, pelos ingredientes utilizados na formulação de dietas, pelas condições sanitárias de criação dos leitões e pela intensidade de estresse do animal. A diferença de pureza, peso molecular, conformação e métodos de extração do betaglucano utilizado nos distintos trabalhos também pode explicar os diferentes resultados observados. Enfim, o mecanismo exato pelo qual a suplementação com betaglucano melhora o desempenho de suínos em crescimento não está bem esclarecido.

Os resultados da atividade da enzima SOD encontram-se na Tab. 5.

Tabela 5. Valores da suplementação da enzima superóxido dismutase (SOD) de acordo com a adição de betaglucano à dieta de suínos

\begin{tabular}{cccccccc}
\multirow{2}{*}{ Parâmetro } & \multicolumn{4}{c}{ Suplementação de betaglucanos da dieta $(\mathrm{g} / \mathrm{t})$} & \multirow{2}{*}{ CV } \\
& 0 & 60 & 120 & 180 & 240 & $(\%)$ \\
\hline Atividade da SOD (U/mg proteína) & 1,46 & 1,56 & 1,35 & 1,40 & 1,37 & 12,26 \\
\hline
\end{tabular}

Não houve efeito $(\mathrm{P}>0,05)$ dos níveis crescentes de betaglucano na dieta sobre a atividade da enzima SOD. Alves e Santurio (2006), ao avaliarem o efeito da inclusão de betaglucano em dietas de coelhos acometidos experimentalmente, e de maneira controlada, por pitiose, encontraram efeito significativo do tratamento com betaglucano sobre a atividade da enzima SOD. A adição de compostos de potencial ação prébiótica às dietas nem sempre se reflete da mesma forma sobre a resposta biológica, o que pode estar relacionado à dosagem adicionada ou à intensidade de estresse do animal.
Os resultados do ELISA, de acordo com a densidade ótica (DO) e a porcentagem de inibição, encontram-se, respectivamente, nas Tab. 6 e 7 .

Sabe-se que houve ativação do sistema imune, pois ao ELISA, 30 dias após a vacinação $\left(\mathrm{t}_{2}\right)$, os animais foram considerados positivos para $M$. hyopneumonia. Entretanto, não houve efeito $(\mathrm{P}>0,05)$ dos tratamentos sobre a densidade ótica e sobre a porcentagem de inibição, demonstrados no teste de ELISA (Fig. 3 e 4).

Tabela 6. Valores da densidade ótica obtida pelo ELISA de acordo com a adição de betaglucano à dieta de suíno

\begin{tabular}{cccccc}
\hline \multirow{2}{*}{ Período } & \multicolumn{5}{c}{ Adição de betaglucano $(\mathrm{g} / \mathrm{t})$} \\
\cline { 2 - 6 } & 0 & 60 & 120 & 180 & 240 \\
\hline $\mathrm{t}_{0}$ & 1,4 & 1,37 & 1,39 & 1,35 & 1,4 \\
$\mathrm{t}_{1}$ & 1,18 & 1,19 & 1,26 & 1,28 & 1,31 \\
$\mathrm{t}_{2}$ & 0,35 & 0,51 & 0,46 & 0,35 & 0,38 \\
$\mathrm{t}_{3}$ & 0,49 & 0,46 & 0,5 & 0,38 & 0,36 \\
\hline
\end{tabular}

$\mathrm{t}^{0}=$ ao alojamento; $\mathrm{t}^{1}=15$ dias após alojamento; $\mathrm{t}^{2}=30$ dias após alojamento; $\mathrm{t}^{3}=$ ao término do experimento 
Suplementação de betaglucano...

Tabela 7. Porcentagem de inibição, obtidas pelo ELISA, de acordo com a adição de betaglucano à dieta de suínos

\begin{tabular}{cccccc}
\hline \multirow{2}{*}{ Período } & \multicolumn{5}{c}{ Adição de betaglucano $(\mathrm{g} / \mathrm{t})$} \\
\cline { 2 - 6 } & 0 & 60 & 120 & 180 & 240 \\
\hline $\mathrm{t}_{0}$ & 5,32 & 6,18 & 4,94 & 7,5 & 4,91 \\
$\mathrm{t}_{1}$ & 18,61 & 18,49 & 13,92 & 12,82 & 9,47 \\
$\mathrm{t}_{2}$ & 76,94 & 63,61 & 68,6 & 76,09 & 73,48 \\
$\mathrm{t}_{3}$ & 66,4 & 68,65 & 64,99 & 73,65 & 75,22 \\
\hline
\end{tabular}

$\mathrm{t}^{0}=$ ao alojamento; $\mathrm{t}^{1}=15$ dias após alojamento; $\mathrm{t}^{2}=30$ dias após alojamento; $\mathrm{t}^{3}=$ ao término do experimento

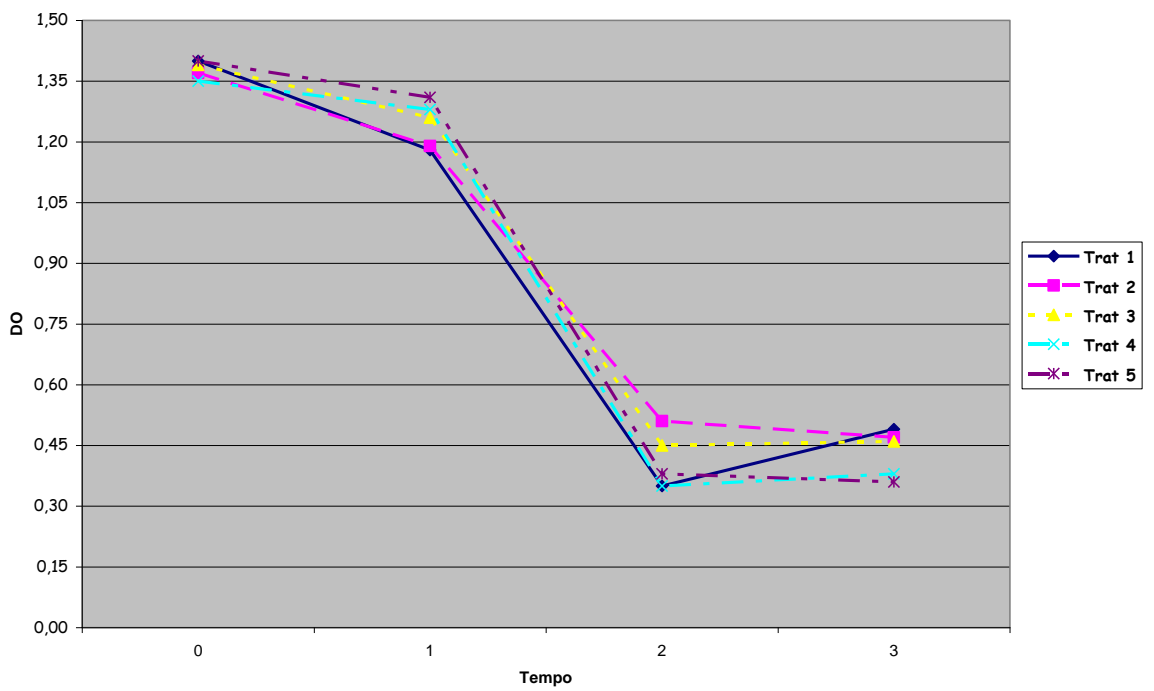

Figura 3. Densidade ótica (DO) pelo teste de ELISA de acordo com a suplementação de betaglucano à dieta de suínos em diferentes tempos.

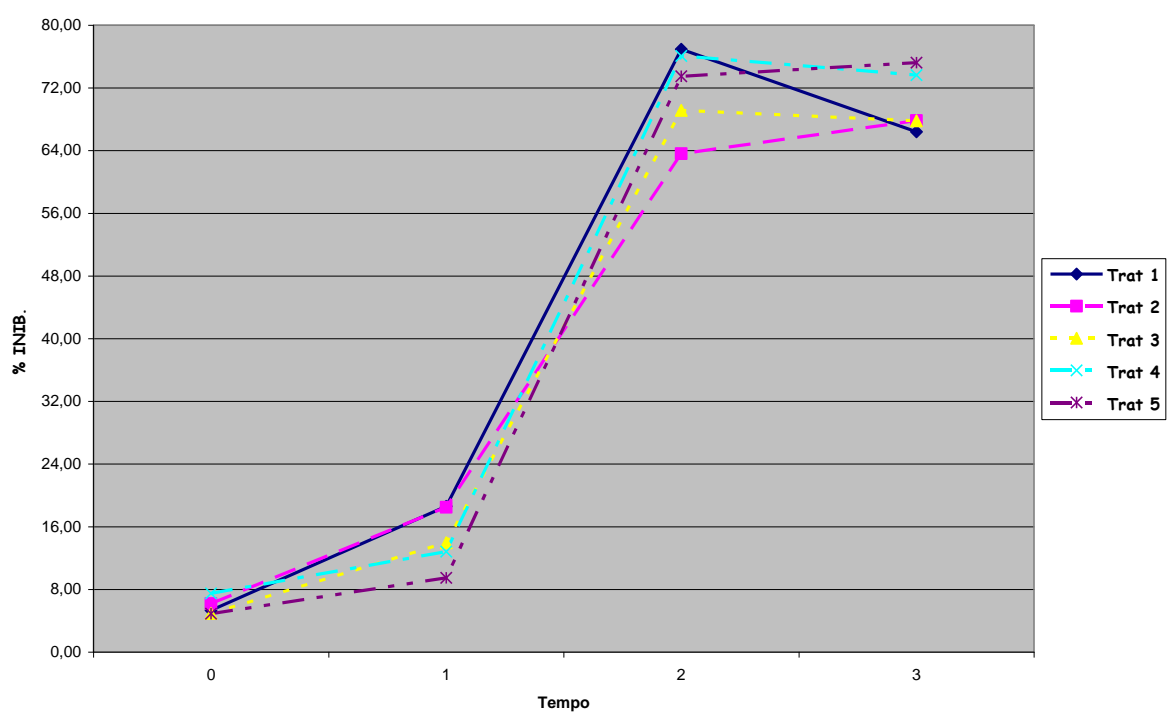

Figura 4. Porcentagem de inibição pelo teste de ELISA de acordo com a suplementação de betaglucanos à dieta em diferentes tempos. 
Estes resultados são semelhantes aos relatados por Hiss e Sauerwein (2003) que concluíram que a suplementação com betaglucano não resulta em nenhum efeito sobre a resposta imune à síndrome reprodutiva e respiratória de suínos. Hahn et al. (2006) verificaram que os títulos de anticorpos contra Pasteurella multocida tipo A e tipo D diferiram significativamente, o que resultou em aumento das células CD4. Os sorotipos A e D são os mais prevalentes em granjas coreanas e grandes variações de animal para animal na resposta à vacina podem ocorrer.

Os resultados encontrados, provavelmente, ocorreram pela condição experimental das instalações e pelo baixo desafio sofrido pelos animais. No entanto, a variabilidade da resposta imunológica sugere que mais estudos são necessários para demonstrar se os betaglucano têm papel diferencial na imunidade de suínos recém-desmamados.

\section{AGRADECIMENTOS}

À Fazenda Boa Esperança, localizada no município de Presidente Olegário, Minas Gerais, os agradecimentos dos autores pelas facilidades proporcionadas para a realização deste experimento - acesso às instalações e cessão dos animais.

\section{REFERÊNCIAS BIBLIOGRÁFICAS}

ALVES, S.H.; SANTURIO, J.M. Efeito Biológico das betaglucanas (Nutricell®, Biorigin) nos tratamentos da pitiose experimental em coelhos. Santa Maria: Laboratório de Pesquisas Micológicas - DMPUFSM, 2006. (Relatório de pesquisa).

BANDEIRA, C.M.; FONTES D.O.; SOUZA L.P.O. et al. Saúde intestinal dos leitões: um conceito novo e abrangente. Cad. Tec. Vet. Zootec., v.54, p.1-97, 2007.

DRITZ, S.S.; SHI, J.; KIELIAN, T.L. et al. Influence of dietary $\beta$-glucan on growth performance, nonspecific immunity and resistance to Streptococcus suis infection in weanling pigs. J. Anim. Sci., v.73, p.3341-3350, 1995.
EICHER, S.D.; McKEE, C.A.; CARROLL, J.A. et al. Suplemental vitamin $C$ and yeast cell wall $\beta$-glucan as growth enhances in newborn pigs and as immunomodulators after an endotoxin challenge after weaning. J. Anim. Sci., v.84, p.2352-2360, 2006.

GIBSON, G.R.; ROBERFROID, M.B. Dietary mudulation of the human colonic microbiota: introducing the concept of prebiotics. J. Nutr., v.125, p.1401-1412, 1995.

HAHN, T.W.; LOHAKARE, J.D.; LEE, S.L. et al. Effects of supplementatation of $\beta$-glucans on growth performance, nutrient digestibility and immunity weanling pigs. J. Anim. Sci., v.84, p.1422-1428, 2006

HISS, S.; SAUERWEIN, H. Influence of dietary $\beta$-glucan on growth performance, lymphocyte proliferantion, specific immune response and heptoglobulin plasma concentration in pigs. $J$. Anim. Physiol. Anim. Nutr., v.87, p.2-11, 2003.

LI, J.; LI, D.F.; XING, J.J. et al. Effects of $\beta$ glucan extracted from Saccharomyces cerevisiae on growth performance and imunological and somatotropic responses of pig challenged with Escherichia coli lipopolysaccharide. J. Anim. Sci., v.84, p.2374-2381, 2006.

LIMA SOARES M.C.; OLIVEIRA A.I.G.; FIALHO E.T. Suinocultura. Lavras: UFLA/FAEPE, 1997. 298p.

MacFARLANE, G.T.; CUMMINGS, J.H. Probiotics and prebiotics: can regulating the activities of intestinal bacteria benefit health? $\mathrm{Br}$. Med. J., v.18, p.999-1003, 1999.

McCRACKEN, B.A.; GASKINS, H. R.; RUWEKAISER, P.J. et al. Diet-dependent and dietindependent metabolic responses underlie growth stasis of pigs at weaning. J. Nutr., v.125, p.28382845, 1995.

ROSTAGNO, H.S. Tabelas brasileiras para aves e suínos: composição de alimentos e exigências nutricionais. 2.ed. Viçosa: UFV, 2005. 186p.

SILVA, E.N. Antibióticos intestinais naturais: bacteriocinas. In: SIMPÓSIO SOBRE ADITIVOS ALTERNATIVOS NA NUTRIÇÃO ANIMAL, 2000, Campinas. Anais... Campinas: CBNA, 2000. p.15-24. 
SISTEMA de análises estatísticas e genéticas SAEG. Versão 7.1. Viçosa. UFV, 2007.

SONCINI, R.A. Restrições do uso de aditivos na alimentação animal: expectativa da agroindústria. In: SIMPÓSIO SOBRE IMPLICAÇÕES SOCIOECONÔMICAS DO USO DE ADITIVOS NA PRODUÇÃO ANIMAL, 1999, Piracicaba. Anais... Piracicaba: CBNA, 1999. p.99-104.
SPRING, P. The effect of dietary mannanoligosaccharides on cecal parameters and the concentration of enteric bacteria in ceca of Salmonella - challenged broiler chicks. Poult. Sci., v.79, p.205-211, 2000.

YASUI, H.; OHWAKI, M. Enhancement of immune response in Peyer's patch cells cultured with Bifidobacterium breve. J. Dairy Sci., v.74, p.1187-1195, 1991. 